\title{
An Indian Study of Computerized Pulmonary Function Tests in Patients Referred to Physiology Department
}

\author{
Amrith Pakkala ${ }^{1}$ and Ashwini K Shetty ${ }^{2 *}$ \\ ${ }^{1}$ Dept of Physiology,Shridevi Institute of Medical Sciences \& Research Hospital, Tumkur, India \\ ${ }^{2}$ Dept of Physiology, MVJ Medical College \& Research Hospital, Hoskote, Bengaluru, India
}

\begin{abstract}
Background: Obesityis amodern day epidemic.Pulmonary function tests are likely to be compromised to varying degrees in these individuals, thus affecting their artificial ventilation under general anesthesia. It is thus important to study the pattern of pulmonary function in these subjects in a group likely to undergo surgery for varying reasons.

Materials and Methods: 30 malesubjects between 45-60 yearsattending the surgical outpatient with a body mass index [BMI] of more than $25 \mathrm{~kg} / \mathrm{m}^{2}$ who qualified as obese and a similar number of subjects with BMI $<25 \mathrm{~kg} / \mathrm{m}^{2}$ as controls were randomly selected. Flow Volume loop, FEV1, FVCand FEV1/FVC were recorded using computerized spirometer.

Results: FEV1,FVC and FEV1/FVC ratio measured in obese patients were significantly reduced ( $p<0.05)$ when compared to normal BMIindividuals.

Conclusion: The incidence of restrictive tendency is more in the obese as compared to controls.As the changes in respiratory mechanics due to obesity are almost completely reversible, early intervention in such patients will ensure lesser chance of complications on the operation table and post-operatively. With the advent of computerized spirometry analysis of flow-volume loops is indeed of great help to the obese.
\end{abstract}

\section{Keywords: PFT,FEV1, FVC, FEV1/FVC, Obesity, Surgical}

\section{Introduction}

Obesity is a modern day epidemic. Obesity must be considered as pathological when the adipose tissue increases to such an extent as to affect health and reduce life expectancy ${ }^{[1]}$. This study is justified in view of the racial variation of pulmonary function parameters. Pulmonary function tests are likely to be compromised to varying degrees in these individuals, thus affecting their artificial ventilation under general anesthesia. It is thus important to study the pattern of pulmonary function in these subjects in a group likely to undergo surgery for varying reasons. The World Health Organization (WHO) estimates that 1.46 billion adults were overweight and 502 million adults (10\% men and 14\% women) were obese by the year 2008 showing that, since the year 1980, the global prevalence of obesity has nearly doubled ${ }^{[2]}$. Further, the WHO predicts nearly 2.3 billion overweight adults in the world by 2015 with more than 700 million of them being obese. Obesity has reached epidemic proportions in India with morbid obesity affecting almost $5 \%$ of the country's female population ${ }^{[3]}$. The medical and surgical pathologies associated with obesity show a corresponding upswing in their frequency of occurrence ${ }^{[4]}$.

The negative physiological effects of obesity on lung function have been demonstrated in numerous studies ${ }^{[5,6,7]}$.
An increase in the abdominal volume preventing full descent of the diaphragm and increase in intra-thoracic fat reducing space for complete lung expansion are hypothesized as the causes of restricted total lung capacity (TLC). ${ }^{[8]}$

In obese subjects, especially on exertion, and in supine position, for example - during surgery or while asleep - the changes enumerated above lead to an increased prevalence of respiratory problems ${ }^{[12]}$. Studies have demonstrated that changes in lung volume can occur at early stages of obesity and are not limited to the morbidly obese individuals ${ }^{[5,6]}$.

Obesity and associated disorders present many difficulties peri operatively during anesthesia and hence require prior planning and awareness of the commonly encountered pitfalls $^{[9]}$.

\section{Materials and Methods}

30 male subjects between 45-60 years attending the surgical outpatient with a body mass index [BMI] of more than $25 \mathrm{~kg} / \mathrm{m}^{2}$ who qualified as obese and a similar number of subjects with BMI $<25 \mathrm{~kg} / \mathrm{m}^{2}$ as controls were randomly selected. Flow Volume loop, $\mathrm{FEV}_{1}$, FVC and $\mathrm{FEV}_{1} / \mathrm{FVC}$ were recorded using computerized spirometer.

Informed consent was obtained from all subjects. 
Ethical clearance was obtained from institutional ethics committee.

\section{Following were the inclusion criteria:}

i) Age group 45-60 years

ii) Blood pressure and Blood glucose levels within normal range. All subjects were free of COPD, asthma, pleural disease and non smokers

The exclusion criteria were:i) Patients who were known cases of restrictive disease and/or taking treatment for the same ii) Patients with chronic systemic illness like Diabetes, Hypertension, Coronary heart disease

iii) Those who were underweight $\left(\mathrm{BMI}<18 \mathrm{~kg} / \mathrm{m}^{2}\right)$

Their Body Mass Index was calculated using Quetelet's formula $^{10}$

$$
\text { BMI }=\frac{\text { Weight (in kilograms) }}{\text { Square of Height (in metres) }}
$$

and they were classified as Obese individuals or as Normal BMI individuals.

Procedure: The testing was carried out between 11AM - 1PM in a well ventilated room. All the subjects were initially familiarised with the instrument used for testing computerised spirometer. SPL-95 Computerised spirometer of FIM company was used to measure PFT parameters. The procedure was explained clearly and sufficient demonstration given. The patient was comfortably seated. Nose clip was applied. Subject was asked to expire air as forcefully and as rapidly as possible, into the mouthpiece of the computerised spirometer, followed by a deep inspiration. This procedure was repeated three times with a gap of about 7 minutes between each maneuver to obtain the best of three values as FVC. Flow Volume loop, Forced expiratory volume in the first second $\left(\mathrm{FEV}_{1}\right)$ Forced vital capacity (FVC) and $\mathrm{FEV}_{1} / \mathrm{FVC}$ were recorded. Each patient repeated the test thrice with a minimum gap of three minutes between any two efforts. The best of the three readings was considered for analysis.

Normal values of FVC and $\mathrm{FEV}_{1}$ indicated normal pulmonary function test (PFT). Low values indicated the presence of disease. When the measured value of $\mathrm{FEV}_{1} /$ FVC was $90 \%$ or more of the predicted value, in the presence of low $\mathrm{FEV}_{1}$ and /or low FVC, it indicated the presence of restriction ${ }^{11}$. Predicted values were calculated based on the spirometry software spl95.00.91. Ethnic correction was done based on Agarwal study in North Indian states ${ }^{3}$.

Thus, they were classified into two groups as follows

Control Group - Normal weight patients (BMI 18- 22.9 kg $\left./ \mathrm{m}^{2}\right)$

Study Group - Obese patients (BMI $>25 \mathrm{~kg} / \mathrm{m}^{2}$ )

Statistical Analysis: Unpaired student t-test was used to determine significance, $p<0.05$ is considered as significant

\section{Results}

Table 1 shows the significantly higher weight and BMI in the study group as compared to control group. This is expected in view of the obese study group.

Table 2 shows that the measured FEV ${ }_{1}$ and $\mathrm{FVC}$ values in the study group were significantly lower when compared to controls. Percentage of predicted value of $\mathrm{FEV}_{1}$ and FVC showed a similar pattern. The measured value of $\mathrm{FEV}_{1} / \mathrm{FVC}$ per se and as percentage of predicted value is significantly reduced in the obese as compared to controls shown in Table 2

Table 1: Comparison of anthropometric data of non-obese \& obese with statistical analysis.

\begin{tabular}{|c|c|c|c|c|}
\hline Parameter & Non-obese & obese & P-value & Remarks \\
\hline Age $(\mathrm{Yr})$ & $52.48 \pm 2.62$ & $52.45 \pm 2.89$ & $<0.05$ & NS \\
\hline Height $(\mathrm{cm})$ & $168.70 \pm 7.50$ & $165.90 \pm 7.24$ & $<0.05$ & $\mathrm{NS}$ \\
\hline Weight $(\mathrm{kg})$ & $60.06 \pm 5.64$ & $99.43 \pm 6.26$ & $<0.001$ & VHS \\
\hline BMI $\left(\mathrm{kg} / \mathrm{m}^{2}\right]$ & $22.02 \pm 2.47$ & $30.60 \pm 1.75$ & $<0.001$ & VHS \\
\hline
\end{tabular}

NS $=$ Not significant, $P<0.05$ Significant, $P<0.01$ Highly Significant, $P<0.001$ Very Highly Significant

\begin{tabular}{|c|c|c|c|c|c|c|}
\hline \multirow{2}{*}{ Parameter } & & \multicolumn{2}{|c|}{ Control Group Normal BMI. } & \multicolumn{2}{|c|}{ Study Group Obese } & \multirow{2}{*}{ p value } \\
\hline & & Mean & SD & Mean & SD & \\
\hline \multirow[t]{2}{*}{$\mathrm{FEV}_{1}(\mathrm{~L})$} & Measured & 2.93 & 0.70 & 1.72 & 0.56 & $<0.001$ \\
\hline & $\%$ of Predicted & 91.0 & 7.15 & 72.86 & 16.66 & \\
\hline \multirow[t]{2}{*}{$\mathrm{FVC}(\mathrm{L})$} & Measured & 3.42 & 0.81 & 1.93 & 0.65 & $<0.001$ \\
\hline & $\%$ of Predicted & 97.47 & 5.83 & 68.01 & 15.61 & \\
\hline \multirow[t]{2}{*}{$\mathrm{FEV}_{1} / \mathrm{FVC}(\%)$} & Measured & 83.62 & 4.35 & 83.42 & 5.81 & $<0.05$ \\
\hline & $\%$ of Predicted & 96.82 & 3.1 & 92.92 & 7.21 & \\
\hline
\end{tabular}

Table 2: Comparison of $\mathrm{FEV}_{1}$ values - Measured \& as Percentage of Predicted. 


\section{Discussion}

Adipocyte is no longer considered as a depot for fat storage alone. Studies have proved that it to be an endocrine cell releasing many chemical mediators like leptin (an energy balance regulating hormone), cytokinins like tumour necrosis factor (TNF) -alpha and interleukin(IL)-6, complement factors such as factor-D, prothrombotic factors such as plasminogen activator inhibitor(PAI)-1 and angiotensinogen which is a component of the blood pressure regulating system. Such mediators are involved in lipid homeostasis, insulin sensitivity, blood pressure control, coagulation, vascular health and contribute to obesity-related pathologies ${ }^{[7,11]}$. Heredity of body weight is similar to that for height. Obesity is seen to run in families but the inheritance pattern is not Mendelian ${ }^{[8]}$. Whatever the role of the genes, it is clear that the environment plays a key role in the development of obesity ${ }^{[12]}$.

Indians are genetically susceptible to weight accumulation, especially around the waist. In males, abdominal obesity is more common. In such cases, excess adipose tissue is present in the anterior chest wall, anterior abdominal wall and around visceral organs. This results in chest wall being less compliant and lowered respiratory muscle endurance causing airway resistance and work of breathing to increase correspondingly ${ }^{[7,13]}$. Diaphragmatic movement is hindered resulting in diminished basal lung expansion during inspiration and ventilation-perfusion abnormalities with arterial hypoxemia due to closure of peripheral lung units $^{[14]}$

Vital capacity (VC) and TLC are decreased in obesity. It is not certain as to the factors causing this reduction but there are few hypotheses - The increased abdominal volume may lead to decreased descent of diaphragm during inspiration and consequently the thoracic expansion reduces. Abdominal elasticity increases along with an expansion of the ring of insertion of the diaphragm to the lower rib cage ${ }^{[15,16]}$. Intrathoracic fat is more in obese individuals which compete with the lungs for space within the intrathoracic cavity. This mechanism would be analogous to that proposed for the restrictive pattern associated with chronic heart failure, which is much improved after cardiac transplantation ${ }^{[8]}$.

Reduced TLC was formerly thought to occur only in massively obese subjects but has now been found in some subjects with less severe obesity also ${ }^{[6]}$. Prospective studies have revealed that weight gain is associated with loss of pulmonary function while weight loss is associated with increase in $\mathrm{VC}^{[6,7]} \mathrm{A}$ reduced FVC on spirometry in the absence of a reduced $\mathrm{FEV}_{1}$-to-FVC ratio suggests a restrictive ventilatory problem. Measuring the TLC and residual volume (RV) can confirm the restrictive tendency suggested by spirometry. Restrictive lung diseases exhibit reduced TLC percentage with relative preservation of the RV/TLC percentage in fibrosis, a reduced inspiratory capacity and expiratory reserve volume (ERV) in neuromuscular disease, and severe reduction of the ERV in extreme obesity ${ }^{[17]}$.

Because this class of patients notoriously have a decreased functional residual capacity (FRC), they will desaturate quickly ${ }^{[4]}$; this will be seen prior to intubation (period of apnoea) and after extubation, if oxygen isn't maintained.

While no single test can effectively predict intra-operative and postoperative morbidity \& mortality from pulmonary complications, the $\mathrm{FEV}_{1}$ obtained from good quality spirometry is a useful tool. When the $\mathrm{FEV}_{1}$ is greater than 2 $\mathrm{L}$ or $50 \%$ of predicted value, major complications are rare. Operative risk is heavily dependent on the surgical site, with chest surgery having the highest risk for postoperative complications, followed by upper and lower abdominal sites. Among the most important modifiable patientrelated factors associated with increased operative risk for pulmonary complications is obesity ${ }^{[17]}$. The deleterious effect of weight gain is, to a large extent, reversible. Improvement in pulmonary mechanics is the great advantage gained by obese patients upon losing weight. ${ }^{[18]}$

\section{Conclusion}

The incidence of restrictive tendency is more in the obese as compared to controls. As the changes in respiratory mechanics due to obesity are almost completely reversible, early intervention in such patients will ensure lesser chance of complications on the operation table and postoperatively. With the advent of computerized spirometry analysis of flow-volume loops is indeed of great help to the obese.

\section{References}

1. Health Implications of Obesity. NIH Consensus Statement Online 1985 Feb 11-13 [cited 2012 Nov 27]; 5(9):1-7

2. World health statistics - A snapshot of global health. Published by World Health Organisation. Available online at http://www.who.int/gho/publications / world_health_ statistics /EN_WHS2012_Brochure.pdf

3. Agrawal PK. Emerging Obesity in Northern Indian States: A Serious threat for Health. Paper presented at IUSSP Conference, Bangkok, held on June 10-12, 2002. Accessed on November 28,2012 from http://212.95.240.146/ Bangkok2002/S7Agrawal.pdf

4. J.P.Adams and P.G.Murphy. Obesity in anaesthesia and intensive care. Br J Anaesth 2000; 85(1): 91-108

5. DS DeLorey, BL Wyrick and TG Babb. Mild-to-moderate obesity: implications for respiratory mechanics at rest and 
during exercise in young men. International Journal of Obesity (2005) 29, 1039-1047

6. Jones RL, Nzekwu MM. The effects of body mass index on lung volumes. Chest 2006;130: 827-833.

7. Ochs-Balcom HM, Grant BJB, Paola Muti, Sempos CT et al. Pulmonary Function and Abdominal Adiposity in the General Population. Chest 2006; 129(4): 853-862

8. R. A. Watson, N. B. Pride, E. Louise Thomas et al. Reduction of Total Lung Capacity in Obese Men: Comparison of Total Intrathoracic And Gas Volumes. J Appl Physiol 2010; 108:1605-1612.

9. Christopher Zammit, Helen Liddicoat, Ian Moonsie, Himender Makker. Obesity and respiratory diseases. International Journal of General Medicine 2010:3: 335-343

10. Misra A, Chowbey P, Makkar BM, Vikram NK, Wasir JS, Chadha D, et al. Consensus statement for diagnosis of obesity, abdominal obesity and the metabolic syndrome for Asian Indians and recommendations for physical activity, medical and surgical management. J Assoc Physicians India 2009; 57: 163-70.

11. Durga Prasada Rao and Venkateswara A Rao: Morbidly obese parturient: Challenges for the anaesthesiologist, including managing the difficult airway in obstetrics. What is new: Indian J Anaesth. 2010 Nov-Dec; 54(6): 508-521.

12. Stephen O'Rahilly and I.Sadaf Farooqi. Genetics of obesity. Phil. Trans. R. Soc. B 2006; 361: 1095-1105

13. Babb, Ranasinghe, Comeau, et al. Dyspnea on Exertion in Obese Women. Am J Respir Crit Care Med 2008; 178: $116-123$

14. Wannamethee SG, Shaper AG, Whincup PH. Body fat distribution, body composition, and respiratory function in elderly men. Am J Clin Nutr 2005;82:996 -1003

15. Leduc D, Cappello M, Gevenois PA, De Troyer A. Mechanics of the canine diaphragm in ascites: a CT study. J Appl Physiol 2008;104: 423-428

16. Leduc D and De Troyer A. Dysfunction of the canine respiratory muscle pump in ascites. J Appl Physiol 2007;102: 650-657

17. McCarthy $\mathrm{K}$, Dweik R A et al. Pulmonary function testing. Available online at emedicine.medscape.com/ article/303239-overview

18. Mahajan S, Arora AK, Gupta P. Obesity and Spirometric Ventilatory Status Correlation in Adult Male Population of Amritsar. National Journal of Physiology, Pharmacy and Pharmacology 2012; 2(2): 93-98

*Corresponding author:

Dr. Ashwini K Shetty, Dept of Physiology, MVJ Medical College \& Research Hospital, Hoskote, Bengaluru, India 